\title{
Identification of potent inhibitors for p38 protein of human through in silico analysis
}

M Naga Lakshmi*, Dibyabhaba Pradhan, Manne Munikumar and Amineni Umamahwari**

SVIMS Bioinformatics Centre, Department of Bioinformatics, SVIMS University, Tirupati

Pin-517507, India,Email: svims.btisnet@nic.in

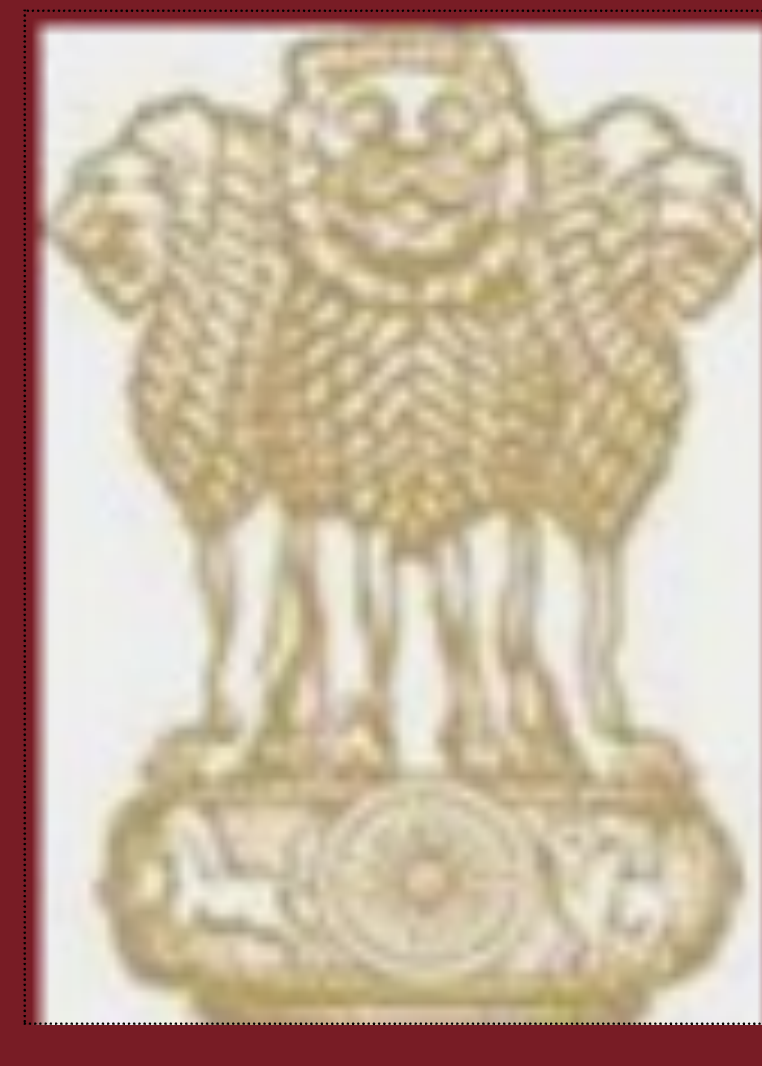

*Presenting author ;** Corresponding author

\section{Key points}

- p38 Mitogen activated protein kinase is a serine/threonine protein kinase

It mediats the signaling process activated by the MKK6 and MKK and acts as positive regulator in phosphorylating the cytoskeleton protein Tau, Stathmin and $\mathrm{eEF}_{2} \mathrm{~K}$ along with keratinocyte differentiation.

Over-expression leads to tumor development by impairing the ERK1/2 -AP1 pathway.

Herein an in silico approach was practiced to hit upon more potent inhibitors for human p38 protein.

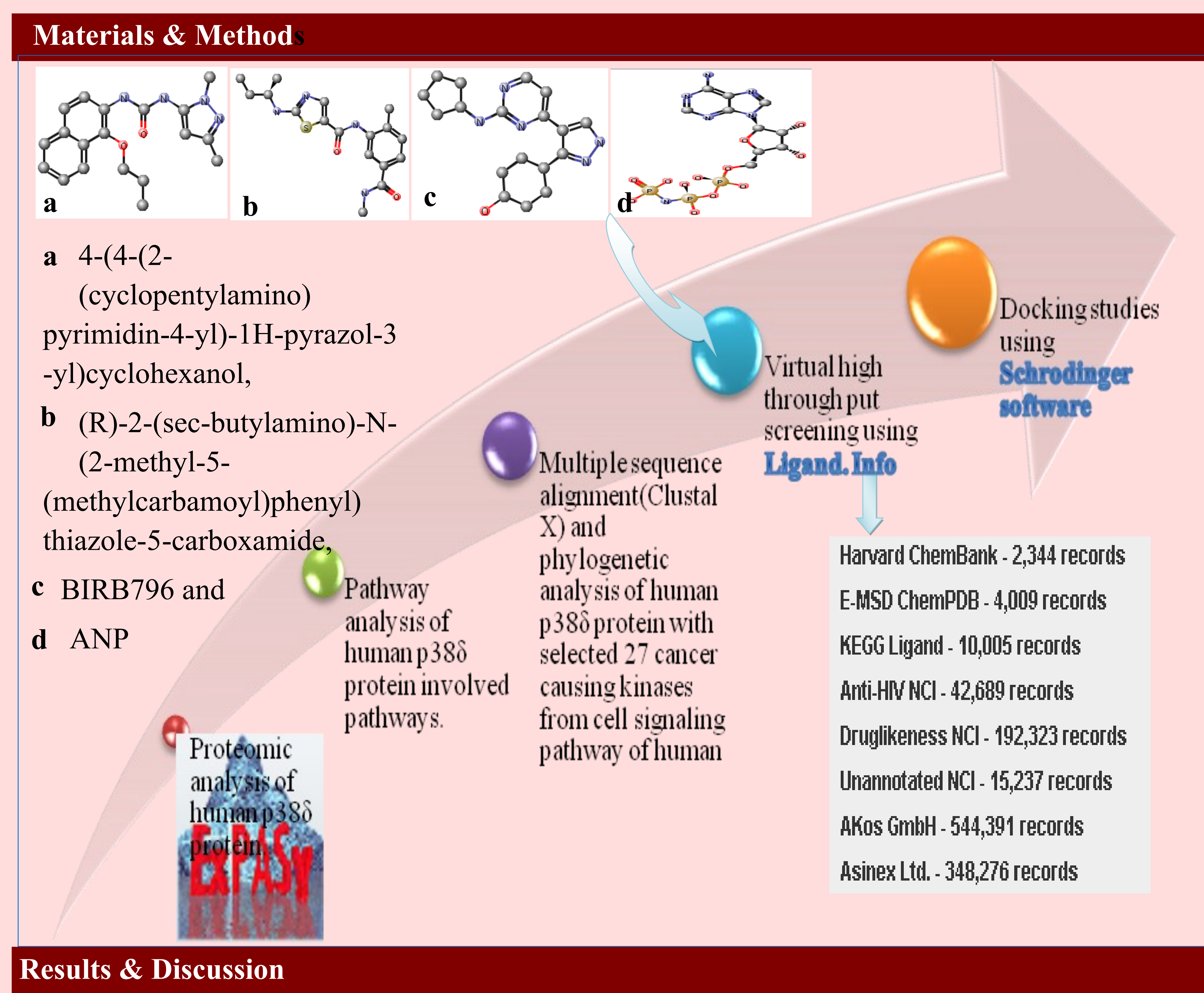

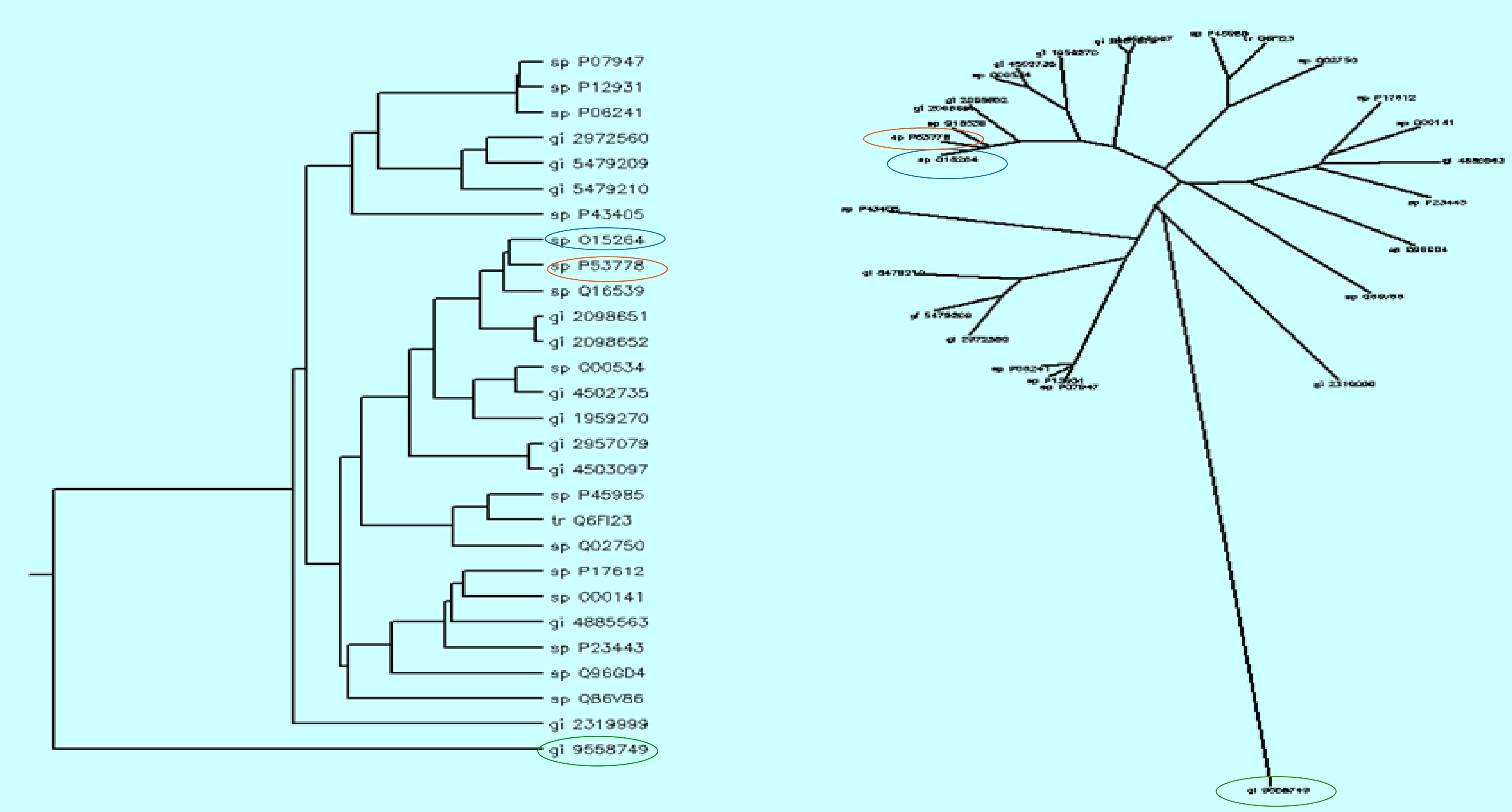

Figure 1: Rooted and unrooted representation of human p38 protein with 27 selected cancer causing kinases from cell signaling pathway of human proteins in human.

Human p38 $\delta$ is closely related to $\underline{p 38 \gamma}$ and distantly related to eukarvotic elongation factor 2 kinase of humain.

Blue color: out group, Red color: closely related, Green color: distantly related

Figure 2: In response to hyper osmotic stress both the isoforms p38 delta and gamma mediates the signaling course of action activated by the MKK6 and MKK3. p38delta ${ }^{+}$acts as encouraging regulator in phosphorylating the cytoskeleton protein Tau, Stathmin and $\mathrm{eEF}_{2} \mathrm{~K}$. Modification takes place in the protein substrates in retort to hypoxia involved reactions by $\mathrm{p} 38$ delta along with p38gamma.

\section{Acknowledgement}

Authors are highly thankful to DBT, Ministry of science and technology, Govt. of India for supporting research activities at SVIMS Bioinformatics centre. We are also thankful to Dr. B. Vengamma, Director, SVIMS, for her constant encouragement and support.

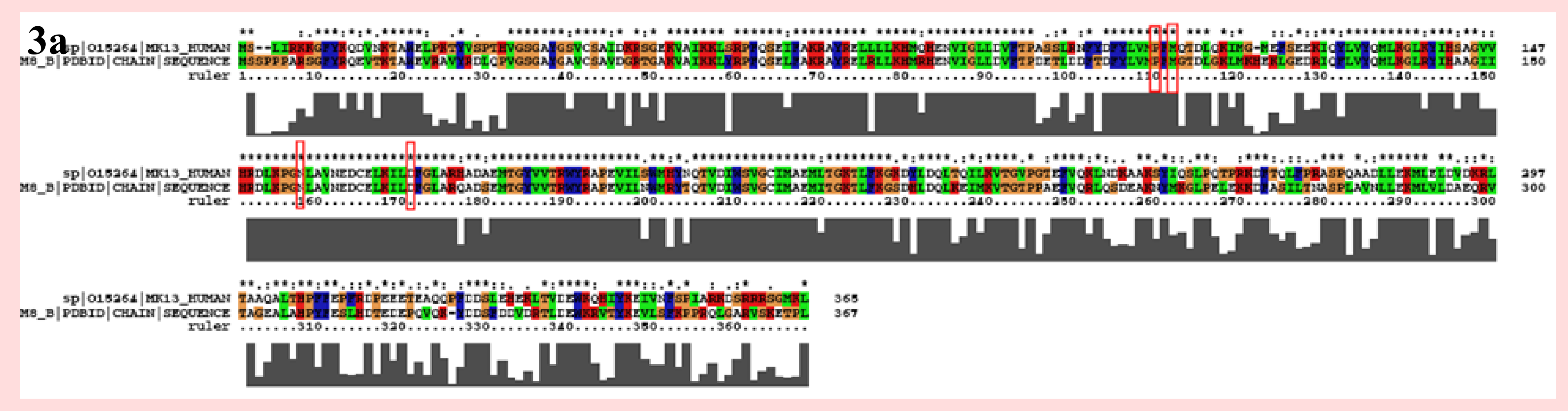

Active site of the $\mathrm{p} 38 \delta$ protein were predicted through comparative analysis with closely related co-crystal structure p38y (94\% identity). The active site residues are Pro108, Met110, Asn 155 and Asp168.

Figure 3:(a) Post Script file of multiple aligned $\mathrm{p} 38 \delta$ with p38 .(b) Crystal Structure of p38 (RCSB)

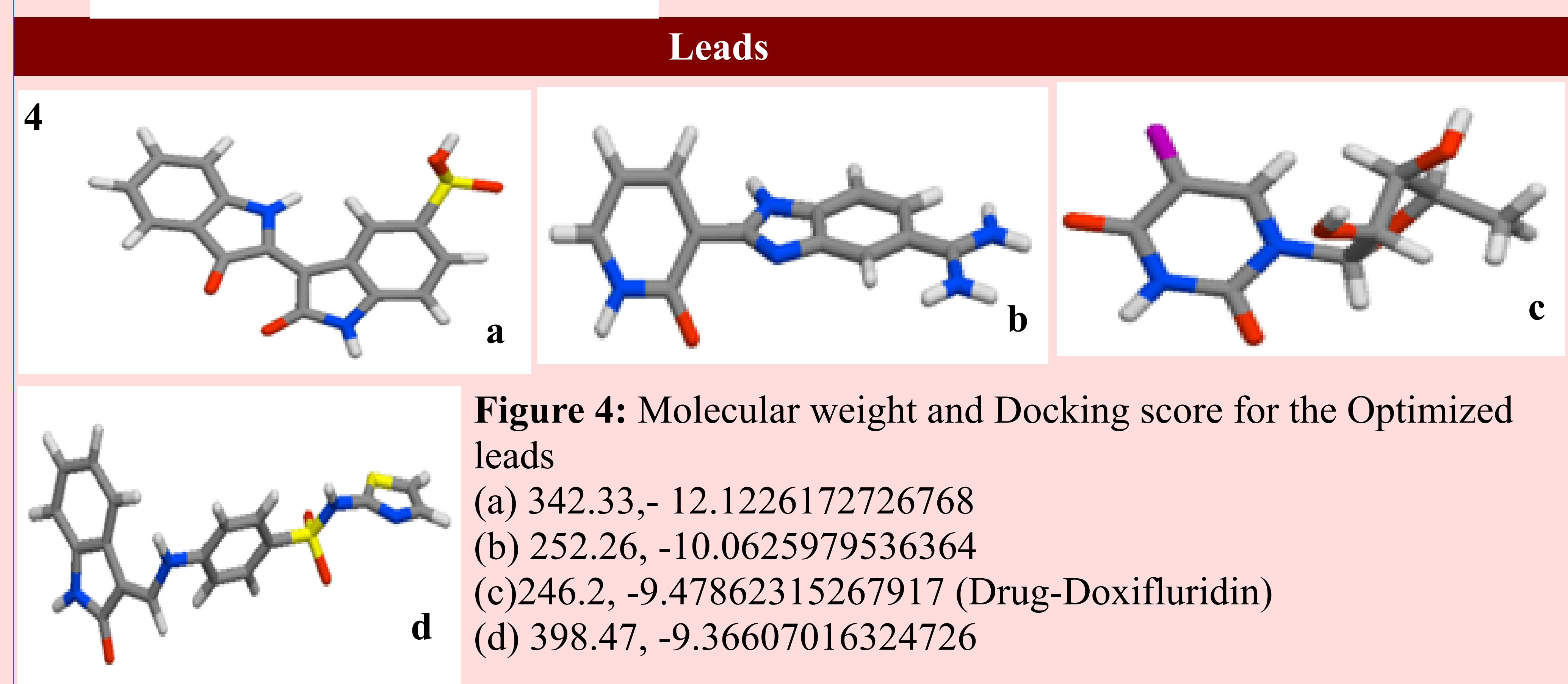

Docking Interaction with the Lead ' 1 '

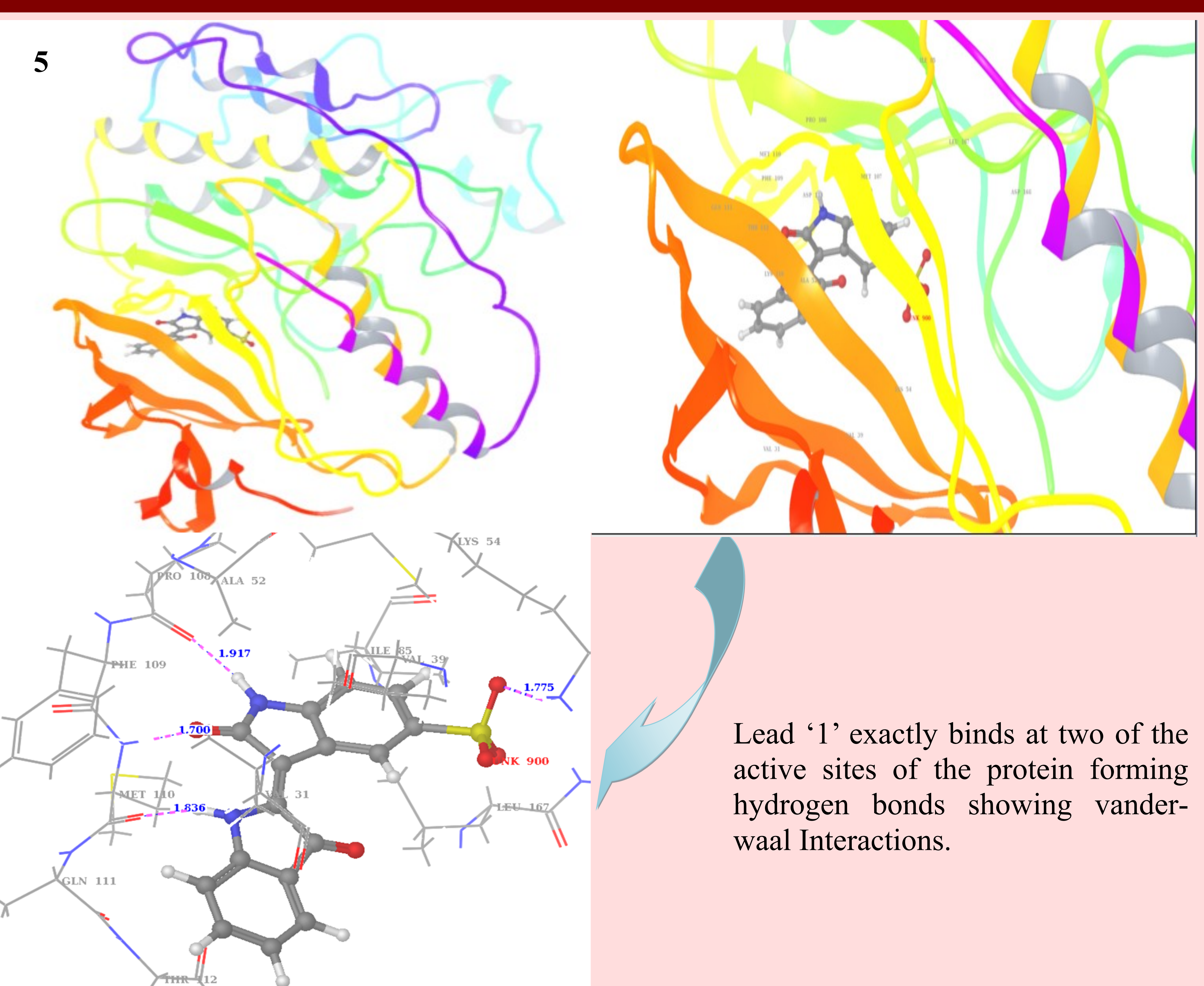

Figure 5: Docking interface of lead ' 1 'with the $\mathrm{p} 38 \delta$

\section{Conclusion}

The computational conduit presented in this work is a useful tool for the design of structurally stable leads with altered affinity for ligand binding, considerably reducing the number of ligands to be experimentally tested. Ligands are screened by docking simulation and stability evaluation followed by a rationally driven selection of those presenting the requisite characteristics. Through computational analysis four lead molecules were suggested as potential inhibitor of p38 delta. Lead1 with lowest docking score and good correlation with published inhibitor would be proposed for synthesis and clinical trial for p38 delta inhibition. 